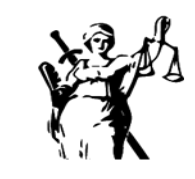

JUSTICIA

ISSN impreso 0124-7441
ISSN digital 2590-4566

\title{
El intercambio académico ante la pandemia Covid-19: caso específico de los estudiantes de Educación Superior de la Universidad Autónoma de Nuevo León
}

\author{
Academic exchange at the Covid-19 pandemic: specific case \\ of students of Higher Education of the Universidad Autónoma \\ de Nuevo León
}

\begin{abstract}
iD
Sandy Elizabeth Martínez Lara

Universidad Autónoma de Nuevo León, Monterrey, México sandymartinezlara@gmail.com

\author{
Emma Melchor Rodríguez
}

Universidad Autónoma de Nuevo León, Monterrey, México
\end{abstract}

Oswaldo Leyva Cordero

Universidad Autónoma de Nuevo León, Monterrey, México

Recibido: 14 de mayo de 2020 / Aceptado: 26 de julio de 2020 https://doi.org/10.17081/just.26.39.4801

\section{Resumen}

La naturaleza subjetiva de los conflictos y su inminencia en las relaciones humanas suscita la constante reflexión de como dinamizarlos para alcanzar acuerdos oportunos, asertivos y sostenibles al interior de las organizaciones. En la búsqueda de esta dinamización surge mediación de los conflictos interpersonales en el ámbito laboral como una alternativa válida y confiable. Este artículo de reflexión se constituye en una investigación documental que tiene por objetivo aproximarse a visibilizar el rol del mediador al interior de las organizaciones, delimitar planes de intervención y/o políticas de gestión del conflicto desde la alta gerencia, así como crear material formativo sólido y rigurosos, que sea soporte y guía para las áreas de recursos humanos y/o comités de Seguridad y Salud en el Trabajo.

PalABras CLAVE: mediación, conflicto laboral interpersonal, riesgo psicosocial, gestión, salud mental laboral.

\begin{abstract}
The subjective nature of conflicts and their imminence in human relationships raises constant reflection on how to dynamize them to reach timely, assertive and sustainable agreements within organizations. In the search for this dynamization, mediation of interpersonal conflicts in the workplace arises as a valid and reliable alternative. This article of reflection is constituted in a documentary research that aims to approach to make visible the role of the mediator within organizations, define intervention plans and / or conflict management policies from senior management, as well as create solid training material and rigorous, that is support and guide for the areas of human resources and / or committees of Safety and Health at Work.
\end{abstract}

KEYWORDS: mediation, interpersonal labor conflict, psychosocial risk, management, occupational mental health.

Como Citar: Martínez Lara, S. E., Melchor Rodríguez, E., \& Leyva Cordero, O. (2021). El intercambio académico ante la pandemia Covid-19: caso específico de los estudiantes de Educación Superior de la Universidad Autónoma de Nuevo León. Justicia, 26(39), 79-90. https://doi.org/10.17081/just.26.39.4801 


\section{Introducción}

En la actualidad, la pandemia ocasionada por el virus Covid-19 vino a generar múltiples cambios en el sector empresarial y el sector académico. En este sentido, la Educación Superior ha presentado grandes transformaciones en los modelos académicos, la innovación en el uso de tecnología y capacitación a profesores y estudiantes; sin embargo, todo esto condujo a una adecuación a los programas de movilidad académica internacionales que son ofertados por las Instituciones de Educación Superior.

Asimismo, durante el mes de marzo 2020 tiempo en que fue declarada la pandemia a nivel internacional por la Organización Mundial de la Salud, un gran número de estudiantes se encontraban realizando su movilidad académica en el extranjero situación que ocasiono incertidumbre y ansiedad sobre la situación que se estaba presentado.

Por tal motivo, esta investigación muestra los resultados obtenidos de una encuestada aplicada de manera digital durante los meses de mayo, junio y julio a estudiantes de Educación Superior de la Universidad Autónoma de Nuevo León que se encontraban realizando su programa de movilidad académica en el extranjero. Asimismo, se analiza el grado de consumo y conocimiento de información referente al virus Covid-19 por los estudiantes. Los objetivos principales radican en determinar la importancia del consumo de información sobre el Covid-19 por los estudiantes, conocer la situación que atravesaron e identificar los sentimientos percibidos, es decir, comprender el estado de ánimo, conocer el apoyo brindado por la institución receptora hacia los estudiantes extranjero y las medidas de prevención que tomaron durante los meses de pandemia. Todo esto a través de una metodología cuantitativa de corte transversal y correlacional, mediante diversas pruebas estadísticas de fiabilidad, descriptivas y comprobación de hipótesis, que arrojaron resultados significativos para la investigación; en donde se demuestra que las variables de investigación influyen positivamente en los estudiantes que se encontraban de movilidad académica al momento de surgir la pandemia por Covid-19.

\section{El impacto del intercambio académico en las Instituciones de Educación Superior}

La internacionalización de la Educación Superior es uno de los temas sobresalientes en los últimos años. De acuerdo con De Wit (2011) el tipo de universidad y el modo de operación de la universidad determinará el grado de internacionalidad de la institución. Es así como, el contexto educativo se vuelve un modelo importante de cooperación entre las universidades. Al mismo tiempo, los programas educativos de las múltiples universidades que existen en el mundo determinan la calidad de estudiantes que egresan de las mismas.

En este mismo sentido, las universidades de educación superior realizan estrategias para lograr ser internacionales. Es decir, la internacionalización de la Educación Superior universitaria es aquel proceso de integración y combinación entre la dimensión internacional, intercultural y global en los procesos de enseñanza (De Wit, 2011). Por tal motivo, la internacionalización es considerada como un factor fundamental para la mejora de calidad y la eficiencia de las universidades, dando como resultado, una educación de excelencia, así como las universidades buscan formar profesionales con conocimiento para crear modelos de desarrollo y crecimiento solido. 
Ante esto, las estrategias de internacionalización pueden varían entre una y otra, sin embargo, todos tienen un objetivo en común lograr la internacionalización. Asimismo, es importante mencionar que la realidad y prioridad de las instituciones cambian constantemente; esto debido a diversos factores entre los que destacan el sistema de gobierno, el crecimiento económico del país, las tecnologías de información, la comunicación entre las diversas autoridades, entre otras.

Es así como, Knight (2008) afirma que existen diversos niveles de internacionalidad de acuerdo con las necesidades de cada institución. Por tal motivo, los niveles cambian si lo que se busca es transformar una institución para que sea más global, más intercultural, y sobre todo con nuevos y mejores métodos de enseñanza. Asimismo, existen otras técnicas de internacionalización, como, por ejemplo, la internacionalización desde casa. De acuerdo con, Beelen (2011) afirma que la internacionalización desde casa es una técnica que busca brindar un grado de internacionalidad a los estudiantes que no realizan una movilidad académica al extranjero, a través de acciones en conjunto con universidades internacionales como lo son: cursos, talleres, intercambio de profesores, conferencias, por mencionar algunas.

En este propósito, la internacionalización de la Educación Superior puede verse analizada desde diversas perspectivas, dicho en otras palabras, la internacionalización desde la perspectiva de un proceso de mejora es utilizada para impulsar la modernización de las universidades en todos sus ámbitos, siendo las más importantes administración, docencia y oferta educativa (Fenoll-Brunet, 2016). Sin embargo, la técnica más utilizada por las Instituciones de Educación Superior para lograr la internacionalización es la movilidad académica, la cual tiene la finalidad de brindar al estudiante la oportunidad de continuar sus estudios en el extranjero, al mismo tiempo, brinda nuevas técnicas de enseñanza y conocimiento de nuevas personas, nuevas costumbres, nuevos entornos y estructuras sociales, entre personas de diferentes países.

Asimismo, Grifoll (2016) menciona que debido a la internacionalización las universidades logran conseguir un impacto, el cual especifica la promoción de la excelencia educativa internacional; en consecuencia, la internacionalización de la Educación Superior busca el desarrollo de las relaciones entre los Estados, entre personas de diferentes culturas e instituciones y sistemas a nivel mundial. Como resultado de esta relación, se logra un contacto entre las naciones que brinda múltiples beneficios, tales como: tolerancia hacia aquel que es diferente a nosotros, desarrollo de habilidades para trabajar en equipos interculturales, tener una visión global, adquirir conocimientos de diferentes culturas, dominio de un segundo e inclusive tercer idioma y enriquecimiento personal y culturas.

\section{Covid-19 y su impacto en las instituciones educativas}

Ante una situación extraordinaria, las Instituciones de Educación Superior aplicaron estrategias de los modelos educativos, con la finalidad de poder continuar con sus procesos de enseñanza. Sin embargo, dichas estrategias mostraron dificultades al momento de emplearlas en su entorno habitual, es decir, se presentaron diversas problemáticas que requirieron su puntual seguimiento y atención.

En primera instancia, el proceso de capacitación a docentes y estudiantes requiere de una planeación estratégica, en donde, se determinan contenidos temáticos como lo son: sistemas operativos, modalidad no escolarizada, herramientas tecnológicas, enseñanza educativa, adecuación de programas educativos y lo más importante educación a distancia. De acuerdo con, Mendoza (2020) la educación a distancia o virtual consiste en una serie de elementos que contribuyen a la educación del estudiante. Asimismo, toma en cuenta la postura del docente, el aprendizaje del alumno, el programa educativo, y el uso de tecnología como un mecanismo para la impartición de clase. Además, la educación a distancia o virtual se distingue 
brindar al estudiante la flexibilidad en tiempos, es decir, el estudiante es capaz de decidir el horario en que realiza sus labores académicas.

Por otra parte, las Instituciones de Educación Superior establecieron herramientas digitales oficiales para los labores académicas, lo que significa, la oportunidad de apertura de nuevas relaciones comerciales entre la instituciones y empresas proveedoras de servicio que, a su vez, satisfacen la necesidad de adecuación y mejora. Es así como, la pandemia generada por el virus Covid-19 vino a revolucionar las estructuras tradicionales del proceso de enseñanza, y afectar una realidad de entorno, por tal motivo, la Comisión Nacional para la Mejora Continua de la Educación realiza una propuesta emergente sobre la educación en su modalidad virtual; dichas propuestas radican en atender el acceso de la población a internet y servicios de telecomunicación; diversificar la enseñanza educativa y tener una visión amplia sobre la situación que se esta viviendo; brindar capacitación a profesores sobre el uso de las herramientas digitales, para tener un mejor servicio en la enseñanza educativa, promover las oportunidades de crecimiento, desarrollo y formación profesional ante la educación digital; garantizar la seguridad del plan educativo y, finalmente, evitar el abandono escolar (Ruiz, 2020).

Asimismo, es importante no olvidar el objetivo que objetivo de la Educación Superior es que el estudiante desarrolle competencias que le brindan la oportunidad y facilidad de desenvolverse en el mundo laboral. Ante esto, Millán et al (2020) afirman que desarrollar competencias en estudiantes resulta ser un gran desafío. Sin embargo, gracias a la pandemia estás competencias pueden verse afectadas; por tal motivo, las Instituciones de Educación Superior deberán de realizar actividades de discusión, análisis metodológicos, e identificar aquellos elementos que aportan alternativas de manejo y participación entre los profesores y estudiantes, con la finalidad de, mecanismos de desarrollo y adecuación de los programas educativos ante esta nueva normalidad.

Si bien es cierto, la pandemia generó múltiples cambios en los modelos tradicionales de educación y ocasionó un descenso en la matrícula, en las oportunidades de estudio, y en el aprendizaje diario. No todo puede ver como negativo, debido a que la pandemia sirvió para realizar propuestas y ampliar el panorama sobre la educación. Pero, sobre todo, la pandemia vino a establecer nuevos mecanismos de comunicación, autoaprendizaje, objetivos de educación, técnicas de enseñanza y desarrollar competencias de acuerdo con cada uno de los perfiles estudiantiles, esto a través de una rotación que permita al estudiante identificar sus fortalezas en el ámbito educativo. Lo que significa que nos estaríamos enfrentando ante un nuevo modelo de enseñanza innovadora y adecuando a cada una de las necesidades de los estudiantes.

Finalmente, la reincorporación académica a aulas podrá representar el desafío más importante que presenten las Instituciones de Educación Superior en los últimos años, esto debido al cuidado y cumplimiento de las medidas de prevención sanitarias.

\section{Medidas de prevención ante el Covi-19.}

El virus Covid-19 o coronavirus, es conocido por causar enfermedades en animales y seres humanos, en donde, afecta órganos como los pulmones, el corazón y los riñones. Asimismo, las personas infectadas por este virus presentan síntomas de fiebre, tos seca, cansancio, dolor muscular, diarrea, dolor de cabeza, pérdida del sentido del olfato y del gusto, así como dificultad para respirar, dolor o presión en el pecho, esto cuando los sintomas son considerados como graves (Morales, 2020). 
En este sentido, la Organización Mundial de la Salud (2020) afirma que existen tres principales maneras de contagio del virus. Persona a persona, este tipo de contagio se da por contacto con una persona infectada, a través de gotas de fluidos de nariz o boca los cuales se desprenden al momento de toser o estornudar. Objetos y superficies infectados, cuando el virus queda penetrado en superficies inanimadas, como el metal, vidrio o plástico por un período de hasta nueve días. En el aire, la persistencia del virus en lugares cerrados puede llegar a ser un punto de contagio debido a la transmisión por pequeñas partículas.

Por tal motivo, las medidas de prevención para el contagio del virus implica el cumplimiento de actividades como, tales como, lavar las manos constantemente con agua y jabón por más de cuarenta segundos verificando, abarcando la zona de dedos, entre dedos y muñeca; cubrir la boca y nariz al momento de toser o estornudar con un el ángulo interno del antebrazo, o bien, con un pañuelo desechable; evitar el contacto directo y sin protección con personas, es decir, mantener una distancia de un metro entre una y otra, por tal motivo, es importante evitar el saludo de mano, beso y abrazo, así como el contacto con manos sucias sobre la nariz, boca y ojos (Clínica IMSS, 2020).

Asimismo, es importante acudir a revisión con el doctor ante la presencia de algún síntoma como fiebre, tos y dificultades para respirar; evitar las reuniones entre familiares y amigos por riesgo de contagio; desinfectar las superficies con las que se tiene contacto mediante el uso de cloro y otros químicos que permitan limpiar las áreas comunes. Finalmente, el cuidado y respeto de estás recomendaciones evitar la propagación del virus en la población, mantener el reguardo social y prestar atención ante cualquier situación de riesgo; buscar alternativas para realizar diversas actividades y mantener una higiene constante.

\section{Método}

\section{Instrumento}

De acuerdo con, Cadena et al (2017) indica que los métodos cuantitativos de corte transversal y correlacional tienen una precisión para los procedimientos de mediación a través de la selección subjetiva de indicadores, es decir, utiliza la selección de conceptos también llamadas variables de medición. Las variables son aquellos conceptos que cumplen con ciertas características y cuentan con dos o más atributos de un evento en especial (Herrera, Cuesta y Escalante, 2016). Asimismo, Parra y Acosta (2010) mencionan que la investigación cuantitativa brinda al investigador datos de calidad que ayudan a la formulación de hipótesis, refuerza el diseño del cuestionario y amplía las conclusiones de la investigación.

Hechas las consideraciones anteriores, está investigación el cuestionario creado por McFadden at al (2020), el cual tiene la finalidad de conocer la percepción de las personas referente al coronavirus. Asimismo, el cuestionario fue adecuado a la versión en español y con un enfoque institucional.

El cuestionario de mediación quedo conformado por un total de 48 ítems, distribuidos de la siguiente manera. La sección uno presenta los datos generales, donde se busca recolectar información del encuestado referente a genero, edad, facultad de procedencia, país y período donde realizó la movilidad. Posteriormente, fueron desarrolladas las cuatro variables de investigación. Para la variable estado de ánimo la integran 8 ítems; la variable información sobre el coronavirus está integrada 13 ítems; la variable postura de la institución receptora conformada por 10 ítems y finalmente, la variable medidas de prevención integrada por 12 ítems. Adicionalmente, el cuestionario utiliza la escala de medición Likert donde 1 es nada y 5 es mucho por cada uno de los reactivos. 


\section{Muestra y procedimiento}

La encuesta fue aplicada de manera online, a través Google Forms durante los meses de abril y junio 2020 mediante un muestreo probabilístico a partir de una muestra representativa de 117 estudiantes de un total de 120 estudiantes de la Universidad Autónoma de Nuevo León que se encontraban de movilidad académica. Adicionalmente, el tamaño de la muestra calculada cuenta con un $95 \%$ de nivel de confianza y un margen de error del $5 \%$.

En este sentido, se obtuvo una participación de 117 alumnos donde el 58.1\% (68) eran mujeres y el 41.9\% (49) corresponde a hombres. La edad promedio de los encuestados radica en 24 años (94\%) y 20, 21 , y 22 años (6\%). En cuanto a la facultad de procedencia, el 14.5\% (17) provenía de la Facultad de Contaduría Pública y Administración, el 12.8\% (15) de la Facultad de Ingeniería Mecánica y Eléctrica, 12\% (14) de la Facultad de Ciencias de la Tierra, el 13.7\% (16) de Escuela Industrial y Preparatoria y el 8.5\% (10) de la Facultad Ciencias Biológicas y un $38.5 \%$ provenientes de otras facultades. Dentro de los principales países donde los encuestadas realizaron su movilidad académica está España con 47.9\% (56), Francia con 24.8\% (29), Alemania con 9.4\% (11), República Checa con 7.7\% (9), Argentina con 4.3\% (5), y un 5.9\% (7) otros países. Finalmente, el periodo de la movilidad quedo enero - junio 2020 70.1\% (82), agosto 2019 - junio 2020 13.7\% (16), agosto 2018 - julio 2020 5.1\% (6) y un $11.1 \%$ otros periodos. La tabla 1 muestra el perfil del encuestado.

Tabla 1. Perfil del encuestado.

\begin{tabular}{|c|c|c|}
\hline & Frecuencia & Porcentaje \\
\hline \multicolumn{3}{|c|}{ Género } \\
\hline Masculino & 49 & $41.9 \%$ \\
\hline Femenino & 68 & $58.1 \%$ \\
\hline \multicolumn{3}{|c|}{ Edad } \\
\hline 20 a 24 años & 102 & 0,94 \\
\hline Otros & 14 & 0,06 \\
\hline \multicolumn{3}{|c|}{ Facultad } \\
\hline FACPYA & 17 & $14.5 \%$ \\
\hline FIME & 15 & $12.8 \%$ \\
\hline FCT & 14 & $12.0 \%$ \\
\hline EIYPTAO & 16 & $13.7 \%$ \\
\hline $\mathrm{FCB}$ & 10 & $8.5 \%$ \\
\hline Otros & 45 & $38.5 \%$ \\
\hline \multicolumn{3}{|c|}{ País } \\
\hline España & 56 & $47.9 \%$ \\
\hline Francia & 29 & $24.8 \%$ \\
\hline Alemania & 11 & $9.4 \%$ \\
\hline República Checa & 9 & $7.7 \%$ \\
\hline Argentina & 5 & $4.3 \%$ \\
\hline Otros & 7 & $5.9 \%$ \\
\hline \multicolumn{3}{|c|}{ Período } \\
\hline Enero - junio 2020 & 82 & $70.1 \%$ \\
\hline Agosto 2019 - junio 2020 & 16 & $13.7 \%$ \\
\hline Agosto 2018 - julio 2020 & 6 & $5.1 \%$ \\
\hline Otros & 13 & $11.1 \%$ \\
\hline
\end{tabular}

Fuente. Elaboración propia 


\section{Fiabilidad}

El coeficiente Alfa de Cronbach permite mediar la confiabilidad con respecto a la homogeneidad o consistencia interna de un instrumento que utiliza escalas de medición (Cohen y Swerdlik, 2016). Así como también, determina el grado en que los ítems se relacionan; entre los valores aceptados destaca un alfa mayor a 0.60 para demostrar que los ítems tiene confiabilidad.

Por tal motivo, el estadístico utilizado para demostrar la fiabilidad del cuestionario fue el coeficiente de relación Alfa de Cronbach; en donde se puede apreciar que los ítems que integran el instrumento muestran consistencia interna aceptable. La fiabilidad encontrada para la variable estado de ánimo fue a $=0.749$ considerada como un valor satisfactorio, integrada por 06 elementos, por su parte, para mediar la variable información se presentaron a los encuestados una serie de reactivos relacionados con la manera en que consumen noticias referente al coronavirus obteniendo de Alfa de Cronbach de $a=0.774$ considerado satisfactorio, asimismo, la variable postura de la institución receptora mostro valores muy satisfactorios de Alfa de Cronbach $\mathrm{a}=0.838$, finalmente, la variable medidas de prevención arrojó resultados $\mathrm{a}=0.733$ vistos como valores aceptados. La tabla 2 muestra la estructura de fiabilidad de las variables.

TABLA 2. FIABILIDAD AlFA DE CRONBACH

\begin{tabular}{|l|l|l|l|}
\hline \multicolumn{1}{|c|}{ Constructo } & \multicolumn{1}{c|}{$\begin{array}{c}\text { Estadística de fiabilidad } \\
\text { Alfa de Cronbach }\end{array}$} & \multicolumn{1}{c|}{ Elementos } & \multicolumn{1}{c|}{ Confiabilidad } \\
\hline Estado de ánimo & .749 & 6 & Aceptada \\
\hline Información sobre el coronavirus & .774 & 7 & Aceptada \\
\hline Postura de la institución receptora & .838 & 8 & Aceptada \\
\hline Medidas de prevención & .733 & 7 & Aceptada \\
\hline
\end{tabular}

\section{Resultados de investigación}

En el análisis descriptivo, para la variable estado de ánimo (ver tabla 3), se detectó que la mayoría de las personas encuestadas indicaron que presentaron miedo por sus familiares que se quedaron en su país de residencia $(M=3.85, D E=1.093)$, posteriormente, de percibir sentimientos de angustia al enterarse de la noticia $(M=3.81, D E=.928)$, seguido, de sentirse muy preocupados por el brote del virus $(M=3.42$, $D E=$ .853). Con valores menores a la media teórica $(M T=3)$ fue identificado el sentimiento de soledad en el país de recepción $(M=2.21, D E=1.303)$, el riesgo al contagio del virus $(M=2.59, D E=1.219)$ y el regreso anticipado por parte de los estudiantes $(M=1.77, D E=1.003)$. 
TABLA 3. ESTADÍSTICOS DESCRIPTIVOS VARIABLE ESTADO DE ÁNIMO.

\begin{tabular}{|l|c|c|c|c|c|}
\hline & N & Mín & Máx & ME & DE \\
\hline EA1. Estoy muy preocupado por este brote & 117 & 1 & 5 & 3.42 & .853 \\
\hline EA 4. Sentí angustia al enterarme de la noticia & 117 & 1 & 5 & 3.61 & .928 \\
\hline $\begin{array}{l}\text { EA 5. Presente miedo por mis familiares que se quedaron } \\
\text { en mi país }\end{array}$ & 117 & 1 & 5 & 3.85 & 1093 \\
\hline EA 6. Me sentía solo en el país de recepción & 117 & 1 & 5 & 2.21 & 1303 \\
\hline EA 7. Sentí que iba a contagiarme & 117 & 1 & 5 & 2.59 & 1219 \\
\hline EA 8. Me quería regresar lo más pronto posible a casa & 117 & 1 & 5 & 1.77 & 1003 \\
\hline N válido (según lista) & 117 & & & & \\
\hline
\end{tabular}

Fuente. Elaboración propia. Datos obtenidos IBM SPSS. MT =3.

Para el caso de la variable, información sobre el coronavirus, tiene la finalidad de conocer el medio de comunicación más utilizada para estar informados sobre el evaluación del virus, los resultados arrojaron (ver tabla 4) que el medio más utilizado por los estudiantes fueron las conversaciones entre otros compañeros $(M=3.68, D E=1.081)$, seguido por Facebook $(M=2.85, D E=1.334)$, Televisión $(M=2.39, D E=1.581)$, Youtube $(M=2.21, D E=1.292)$ e Instagram $(M=2.09, D E=1.390)$, mientras que, los medios de comunicación menos utilizados por los estudiantes fueron radio $(M=1.78, D E=1.274)$ y WhatsApp $(M=1.79, D E=1.207)$.

TABLA 4. ESTADÍSTICOS DESCRIPTIVOS VARIABLE INFORMACIÓN SOBRE EL CORONAVIRUS

\begin{tabular}{|l|c|c|c|c|c|}
\hline & N & Mín & Máx & ME & DE \\
\hline IC 5. Facebook & 117 & 1 & 5 & 2.85 & 1334 \\
\hline IC 6. Youtube & 117 & 1 & 5 & 2.21 & 1292 \\
\hline IC 7. Instagram & 117 & 1 & 5 & 2.09 & 1390 \\
\hline IC 9. WhatsApp & 117 & 1 & 5 & 1.79 & 1207 \\
\hline IC 11. Radio & 117 & 1 & 5 & 1.78 & 1274 \\
\hline IC 12. Televisión & 117 & 1 & 5 & 2.39 & 1581 \\
\hline IC 13. Conversaciones con otros compañeros & 117 & 1 & 5 & 3.68 & 1081 \\
\hline N válido (según lista) & 117 & & & & \\
\hline
\end{tabular}

Fuente. Elaboración propia. Datos obtenidos IBM SPSS. MT =3.

Posteriormente, la variable postura de la institución receptora mostró resultados significativos para la investigación en donde (ver tabla 5), presentó a los estudiantes que se encontraban de movilidad académica una estrategia para llevar las clases en línea $(M=4.68, D E=.741)$, dio la oportunidad de culminar de manera satisfactoria la movilidad académica a los estudiantes $(M=4.62, D E=.797)$, mostró flexibilidad hacia los estudiantes que no podían acceder a las clases en línea $(M=4.32, D E=.999)$ y, presentaron sentimientos de empatía hacia los estudiantes extranjeros $(M=4.13, D E=1.178)$. Con valores menores y muy similares entre los reactivos se encuentra que los estudiantes recibieron apoyo para realizar trámites administrati$\operatorname{vos}(M=3.75, D E=1.272)$, así como la institución se puso en contacto con los estudiantes extranjeros para asesoría $(M=3.65, D E=1.499)$, proporciono a los estudiantes capacitación para las clases en línea $(M=3.51$, $\mathrm{DE}=1.381)$ y brindo apoyo emocional $(M=3.08, \mathrm{DE}=1.439)$. 
TABLA 5. ESTADÍSTICOS DESCRIPTIVOS VARIABLE POSTURA DE LA INSTITUCIÓN RECEPTORA.

\begin{tabular}{|l|c|c|c|c|l|}
\hline & N & Min & Máx & ME & DE \\
\hline $\begin{array}{l}\text { PI 2. Presentó una estrategia para llevar las clases en } \\
\text { línea }\end{array}$ & 117 & 1 & 5 & 4.68 & .741 \\
\hline PI 3. Recibí capacitación para las clases en línea & 117 & 1 & 5 & 3.51 & 1381 \\
\hline $\begin{array}{l}\text { PI 4. Mostraron flexibilidad hacia los estudiantes que no } \\
\text { podían acceder a las clases en línea }\end{array}$ & 117 & 1 & 5 & 4.32 & .999 \\
\hline $\begin{array}{l}\text { PI 5. La institución se puso en contacto con los estudi- } \\
\text { antes extranjeros para asesoría }\end{array}$ & 117 & 1 & 5 & 3.65 & 1499 \\
\hline PI 6. Recibí apoyo para realizar trámites administrativos & 117 & 1 & 5 & 3.75 & 1272 \\
\hline PI 8. Recibí apoyo emocional por parte de la institución & 117 & 1 & 5 & 3.08 & 1439 \\
\hline $\begin{array}{l}\text { PI 9. Se mostraron empáticos hacía los estudiantes } \\
\text { extranjeros }\end{array}$ & 117 & 1 & 5 & 4.13 & 1178 \\
\hline $\begin{array}{l}\text { PI 10. Pude culminar de manera satisfactoria mi movili- } \\
\text { dad académica }\end{array}$ & 117 & 2 & 5 & 4.62 & .797 \\
\hline N válido (según lista) & & 117 & & & \\
\hline
\end{tabular}

Fuente. Elaboración propia. Datos obtenidos IBM SPSS. MT =3.

Para el caso de la variable, medidas de prevención mostró valores significativos muy similares entre los ítems (ver tabla 6), que demuestran que los estudiantes cumplieron con las medidas de prevención brindadas por el sector salud, los más recurrentes fueron lavarse las manos con agua y jabón ( $M=4.91, D E=.310)$, utilizar desinfectante $(M=4.87, D E=.336)$, quedarse en casa $(M=4.58, D E=.940)$, evitar tocarse manos, ojos, nariz y boca con las manos $\sin$ lavar $(M=4.57, D E=.823)$, cubrir la toz o estornudo con pañuelo, para después tirarlo en un bote de basura $(M=4.48, D E=1.055)$, evitar comer fuera de casa $(M=4.17, D E=1.036) y$, evitar realizar viajes nacionales o extranjeros $(M=3.86, D E=1.217)$.

TABLA 6. ESTADÍSTICOS DESCRIPTIVOS VARIABLE MEDIDAS DE PREVENCIÓN

\begin{tabular}{|l|c|c|c|c|c|}
\hline & N & Min & Máx & ME & DE \\
\hline MP 1. Evitar realizar viajes nacionales o extranjeros & 117 & 1 & 5 & 3.86 & 1217 \\
\hline MP 2. Lavarse las manos con agua y jabón & 117 & 3 & 5 & 4.91 & .310 \\
\hline MP 3. Utilizar desinfectante & 117 & 4 & 5 & 4.87 & .336 \\
\hline $\begin{array}{l}\text { MP 4. Evitar tocarse manos, ojos, nariz y boca con las } \\
\text { manos sin lavar }\end{array}$ & 117 & 1 & 5 & 4.57 & .823 \\
\hline MP 5. Evitar comer fuera de casa & 117 & 1 & 5 & 4.17 & 1036 \\
\hline MP 6. Me quedé en casa & 117 & 1 & 5 & 4.58 & .940 \\
\hline $\begin{array}{l}\text { MP 7. Cubrí la toz o estornudo con pañuelo, para después } \\
\text { tirarlo en un bote de basura }\end{array}$ & 117 & 1 & 5 & 4.48 & 1055 \\
\hline N válido (según lista) & 117 & & & & \\
\hline
\end{tabular}

Fuente. Elaboración propia. Datos obtenidos IBM SPSS. MT =3.

Asimismo, fue realizada una última prueba estadística la cual muestra el grado de correlación que existen entre las variables de investigación. Ante esto, Martínez y Rodríguez (2017) mencionan que la correlación de Pearson indica el grado de relación de variables con valores entre los rangos -1 a 1, en consiguiente, determina la manera en que una variable es influenciada por otra y sus efectos. 
Por tal motivo, la prueba de correlación mostró resultados significativos (ver tabla 7), es decir, que el estados de ánimo mantiene una relación directa con la postura de la institución receptora $(r=-3.06, p=$ 001); valores muy similares presentaron las variables información sobre el coronavirus y las medidas de prevención $(r=.270, p=.003)$, lo que quiere decir que los estudiantes cumplían con las recomendaciones de protección y cuidado que brindaban las organizaciones oficiales de salud del país donde realizaban la movilidad. Hechas las consideraciones anteriores, se puede comprobar la hipótesis de investigación sobre el estado de ánimo, la información sobre el coronavirus, la postura de la institución receptora y las medidas de prevención influyen positivamente en los estudiantes que realizaron una movilidad académica en el extranjero durante el brote del virus Covid-19. Asimismo, se comprueba la relación entre la variable estado de ánimo con la variable postura de la institución receptora y, la variable información sobre el coronavirus con la variable medidas de prevención.

TABLA 7. CORRELACIONES DE INVESTIGACIÓN

\begin{tabular}{|c|c|c|c|c|c|}
\hline & & VEA & VIC & VPI & VMP \\
\hline \multirow{3}{*}{ VEA } & \multirow{3}{*}{$\begin{array}{l}\text { Correlación de Pearson Sig (bilat- } \\
\text { eral) N }\end{array}$} & & & $-.306^{* *}$ & \\
\hline & & & & .001 & \\
\hline & & & & 117 & \\
\hline \multirow{3}{*}{ VIC } & \multirow{3}{*}{$\begin{array}{l}\text { Correlación de Pearson Sig (bilat- } \\
\text { eral) N }\end{array}$} & & & & $.270^{\star \star}$ \\
\hline & & & & & .003 \\
\hline & & & & & 117 \\
\hline \multirow{3}{*}{ VIP } & \multirow{3}{*}{$\begin{array}{l}\text { Correlación de Pearson Sig (bilat- } \\
\text { eral) N }\end{array}$} & $-.306^{* *}$ & & & \\
\hline & & .001 & & & \\
\hline & & 117 & & & \\
\hline \multirow{3}{*}{ VMP } & \multirow{3}{*}{$\begin{array}{l}\text { Correlación de Pearson Sig (bilat- } \\
\text { eral) N }\end{array}$} & & $.270^{* *}$ & & \\
\hline & & & -.003 & & \\
\hline & & & 117 & & \\
\hline
\end{tabular}

Fuente. Elaboración propia. Datos obtenidos IBM SPSS.

\section{Discusiones}

Hecha la revisión de los resultados, se acepta la hipótesis de investigación, debido a que se encontró una relación positiva entre las variables de investigación, mismas que ocasionaron que los estudiantes de Educación Superior de la Universidad Autónoma de Nuevo León pudieran concluir de manera satisfactoria su programa de movilidad académica. Asimismo, fueron detectados diversos elementos que puedan ayudar a establecer un modelo de reacción de los estudiantes al enterarse del virus Covid-19, es decir, los estudiantes presentaron sentimiento de miedo por sus familiares, quienes se encontraban en su país natal, asi como presentaron angustia e incertidumbre al enterarse de la noticia, lo que ocasionó que el estudiante fuera capaz de tomar una decisión sobre sus acciones futuras.

Por otra parte, se logró identificar el medio de comunicación más utilizado por los estudiantes que a diferencia de lo tradicional, el estudiante de movilidad sentía mayor seguridad y confianza con la información proporcionada entre sus mismo compañeros y personas que la que pudieran encontrar en algún medio electrónico. Por tal motivo, es importante que el estudiante comprenda el comportamiento cultural de país donde realiza la movilidad y su desarrollo social entre las personas que lo rodean. 
Igualmente, se identifico que en su totalidad las instituciones receptoras mostraron estrategias para llevar a cabo las clases en línea, con la finalidad de concluir de manera satisfactoria el periodo académico, asimismo, brindaron apoyo al mostrar una postura flexible sobre el acceso a las clases en línea, asistencia y asesoría en trámites administrativos comunicación hacia los estudiantes extranjeros que se encontraban de movilidad.

En cuanto a las medidas de prevención, resulta importante mencionar que los estudiantes cumplieron a medida de lo posible con las recomendaciones emitidas por las instituciones de salud, en donde, lavarse las manos constantemente con agua y jabón, utilizar gel desinfectante, evitar salir de casa, cubrir toz o estornudo un pañuelo, evitar tocarse manos, ojos, nariz y boca con las manos sin lavar, entre otras fueron las medidas de prevención más utilizadas por los estudiantes.

Finalmente, concluimos que, los estudiantes que se encontraban de movilidad académica al momento de surgir la pandemia generada por el virus Covid-19 pudieron completar su programa de movilidad de manera satisfactoria, regresar a su país de manera segura y continuar con su formación universitaria.

Sin embargo, es importante mencionar que se encontró con una relación significativa entre las variables, estado de ánimo con postura de la institución receptora y la variable información sobre el coronavirus y las medidas de prevención; lo que brinda a los investigadores futuras líneas de desarrollo para continuar con el fortalecimiento académico y bibliográfico en materia de educación y Covid-19.

\section{Referencias Bibliografica}

Beelen, J. (2011). La internacionalización en casa en una perspectiva global: un estudio crítico del Informe del 3.er Estudio Global de la AIU. RUSC. Universities and Knowledge Society Journal, 8(2), 85-100.

Cadena, P., Rendón, R., Aguilar, J., Salinas, E., De la Cruz, F., y Sangerman, D. (2017). Métodos cuantitativos, métodos cualitativos o su combinación en la investigación: un acercamiento en las ciencias sociales. Revista Mexicana de Ciencias Agrícolas, 8(7), 1603-1617.

Clínica IMSS. (16 de diciembre de 2020). Todo sobre la prevención del COVID-19. https://climss.imss.gob.mx/ cursos/coronavirus/t2/t2_d2.php

Cohen, R., y Swerdlick, M. (2016). Pruebas y Evaluación Psicológicas. Introducción a las Pruebas y a la Medición. Ciudad de México: McGraw Hill

De Wit, H. (2011). Strategies for the International of Higher Education. A Comparative Study of Australia, Canada, Europe and the United States of America. ISBN-90-74721-04-4.

Fenoll-Brunet. (2016). El concepto de internacionalización en enseñanza superior universitaria y sus marcos de referencia en educación médica. Educación Media, 17(3), 119-127.

Grifoll, J. (2016). External quality assurance agencies and excellent in higher education. Educación Médica, 17(3), 94-96.

Herrera, H., Cuesta, A., y Escalante, J. E. (2016). El concepto de variable: un análisis con estudiantes de bachillerato. Educación Matematíca, 28(3), 217-240.

Knight, J. (2008). Higher Education in Turmoil. The Changing World of Internationalization. Rotterdam: Sense Publishers. 
Martínez, F., y Rodríguez, M.J. (2017). Comportamiento de las correlaciones productomomento y tetracórica-policórica en escalas ordinales: un estudio de simulación. RELIEVE. Revista Electrónica de Investigación y Evaluación Educativa, 23(2), 1-21

Mendoza, L. (2020). Lo que la pandemia nos enseñó sobre la educación a distancia. Revista Latinoamericana de Estudios Educativos (México), (L).

Millán, T., Heresi, C., Díaz, F., Weisstaub, G., y Vargas, N. (2020). La pandemia Covid-19 como oportunidad de reflexión en Educación en Ciencias de la Salud. Rev Chil Pedriatr, 91(49), 489491.

Morales, D. (2020). Acciones del personal de salud del área estomatológica en relación a la Covid-19. Revista Cubana de Estomatología, 57(1).

Organización Mundial de la Salud. (2020). Infection prevention and control during health care when novel coronavirus (nCov) infection is suspected interim guidance. Ginebra. Disponible en: https://apps. who.int/iris/rest/bitstreams/1266296/retrieve

Parra, L., y Acosta, M. (2010). La investigación cuantitativa de acoso psicológico laboral en los sectores de la Educación Superior y de la Salud. Una Revista Sistemática, 6(1), 158-172

Ruiz, G. (2020). Covid-19. Pensar la educación es un escenario inédito. RMIE, 25(8), 229-237. 